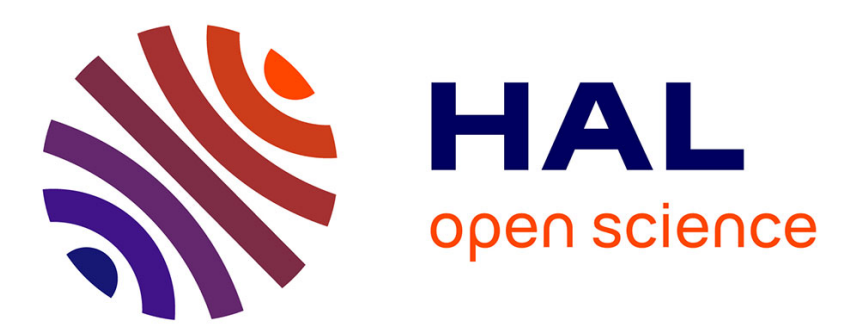

\title{
A Bioinspired Organocatalytic Cascade for the Selective Oxidation of Amines under Air
}

\author{
Martine Largeron, Maurice-Bernard Fleury
}

\section{To cite this version:}

Martine Largeron, Maurice-Bernard Fleury. A Bioinspired Organocatalytic Cascade for the Selective Oxidation of Amines under Air. Chemistry - A European Journal, 2017, 23 (28), pp.6763-6767. 10.1002/chem.201701402 . hal-02384567

\section{HAL Id: hal-02384567 https://hal.science/hal-02384567}

Submitted on 21 Nov 2020

HAL is a multi-disciplinary open access archive for the deposit and dissemination of scientific research documents, whether they are published or not. The documents may come from teaching and research institutions in France or abroad, or from public or private research centers.
L'archive ouverte pluridisciplinaire HAL, est destinée au dépôt et à la diffusion de documents scientifiques de niveau recherche, publiés ou non, émanant des établissements d'enseignement et de recherche français ou étrangers, des laboratoires publics ou privés. 


\section{A Bioinspired Organocatalytic Cascade for the Selective Oxidation of Amines under Air}

\author{
Martine Largeron, ${ }^{*}$ and Maurice-Bernard Fleury
}

various catalytic methods for the aerobic oxidation of amines to imines given the widespread importance of imines as pivotal intermediates in the synthesis of fine chemicals and pharmaceuticals. ${ }^{[7]}$ As a consequence, the use of CuAOs-like catalytic systems has emerged in synthetic planning ${ }^{[8]}$ and organic chemists have designed biomimetic quinone-based catalysts (Scheme 1) with two objectives: ${ }^{[9]}$ 1) to achieve sustainable aerobic amine oxidation reactions; 2) to expand the scope of possible substrates. For example, Wendlandt and Stahl have reported the aerobic oxidation of various primary benzylic amines to imines, at room temperature under $1 \mathrm{~atm}$ of $\mathrm{O}_{2}$, using 5-tert-butyl-2-hydroxybenzoquinone organocatalyst $\mathrm{Q}_{1},{ }^{[10]} \mathrm{a}$ quinone initially developed for biochemical model studies. ${ }^{[6 \mathrm{~d}]}$ Recently, Luo and co-workers have shown that 4-methoxy-5tert-butyl-o-quinone organocatalyst $Q_{2}$ enables effective aerobic oxidation, at room temperature under an $\mathrm{O}_{2}$ atmosphere, of $\alpha$ branched primary benzylic amines considered as poor substrates for CuAOs enzymes. ${ }^{[11]}$ is inexpensive and does not rise to any waste products. However, the direct aerobic oxidation of organic substrates is scarce because the energy barrier for electron transfer from the organic substrate to the oxidant is generally high. To solve this problem, nature has evolved a certain set of synthetic strategies and uses an impressive array of enzyme catalysts. Excellent examples are naturally occurring iron or copper-containing metalloenzymes which have revealed their efficiency as catalysts to perform controlled aerobic oxidations under very mild conditions. ${ }^{[2]}$ Hence, the development of biomimetic methods that utilize environmentally benign oxidants is one of the most important goals in oxidation chemistry today.

Among metalloenzymes, copper amine oxidases (CuAOs) promote selective aerobic oxidation of primary amines to aldehydes, coupled with the reduction of $\mathrm{O}_{2}$ to $\mathrm{H}_{2} \mathrm{O}_{2}$ through the cooperation of a quinone-based organic cofactor 2,4,5trihydroxyphenylalanine quinone (TPQ) and a copper ion. ${ }^{[3]}$ The presence of the copper ion is essential for the production of TPQ from the autocatalytic post-translational oxidation of a tyrosine residue, while the oxidation of the amine substrate is mediated by TPQ without direct involvement of the copper ion. ${ }^{[4]}$ Yet it could play a second role in orienting the TPQ ring correctly in the active site and in facilitating the reduction of $\mathrm{O}_{2}$ to $\mathrm{H}_{2} \mathrm{O}_{2}{ }^{\left[{ }^{5]}\right.}$ Although quinone models that mimic the active site of CuAOs have yielded important insight into the transamination mechanism by which these enzymes operate with benzylamine as the amine substrate ${ }^{[6]}$ surprisingly the synthetic scope of such reactions had received little attention for a long time.

Recently, there has been a boost in the development of

$\left.{ }^{*}\right] \quad$ Dr. Martine Largeron, Prof. Dr. Maurice-Bernard Fleury UMR 8638 CNRS-Université Paris Descartes, Sorbonne Paris Cité, Faculté de Pharmacie de Paris, 4 avenue de l'Observatoire 75270 Paris Cedex 06, France

E-mail:martine.largeron@parisdescartes.fr

Supporting information for this article is given via a link at the end of the document.

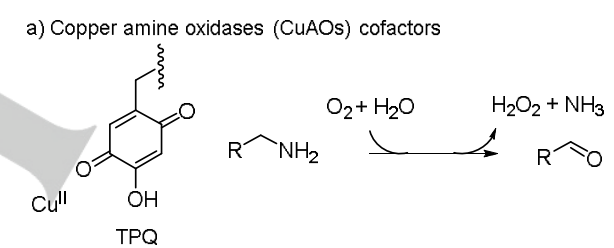

b) Bioinspired catalysts with the chemoselectivity of CUAOs<smiles>CC(C)(C)C1=CC(=O)C(O)=CC1=O</smiles><smiles>[X]C1=C(O)C(C(C)=O)=CC(=O)C1</smiles><smiles></smiles>

(generated in situ)

$X=N H: I M Q$

$X=O: Q_{5}$

c) Bioinspired catalysts with different substrate scope<smiles>[R]C1=CC(=O)C(=O)C=C1C(C)(C)C</smiles><smiles>O=C1C(=O)c2cccnc2-c2ncccc21</smiles>

$Q_{4}$ (phd)<smiles>O=C1C=C(c2ccccc2)c2ccccc2C1=O</smiles>

$Q_{7}$

Scheme 1. Bioinspired quinone-based organocatalysts and cooperative catalytic sytems for the aerobic oxidation of amines to imines.

More challenging, the possibility of expanding the scope to the oxidation of secondary amines, a reaction type that natural CuAOs are not able to accomplish, was also explored. This reaction was possible through the development of cooperative catalytic systems including a quinone-based organocatalyst. For example, the group of Kobayashi has reported that a block copolymer-incarcerated bimetallic Pt/Ir alloy catalyst combined with 4-tert-butyl-o-quinone $Q_{3}$ as the redox-active organic cofactor allowed the aerobic oxidation of secondary amines to imines, at $30^{\circ} \mathrm{C}$ under $1 \mathrm{~atm}$ of $\mathrm{O}_{2},{ }^{[12]}$ while Doris and coworkers have described a similar synergistic action of $\mathrm{Rh}$ 
nanoparticles, supported on carbon nanotubes as co-catalysts with 4-tert-butyl-o-quinone $Q_{3}$ for the aerobic dehydrogenation of $\mathrm{N}$-heterocycles, at room temperature under ambient atmosphere [13] Although these two reaction systems share common characteristics with CuAOs such as the use of a quinone-based organocatalyst together with a metal co-catalyst, mechanistic studies revealed divergence in the reaction pathways because secondary amines are not compatible with the enzymatic transamination mechanism and often serves as inhibitors through the formation of irreversible covalent adducts. ${ }^{[14]}$ Accordingly, Wendlandt and Stahl have brought definitive evidence for a non-biomimetic addition-elimination pathway involving a hemiaminal intermediate which was characterized by NMR spectroscopy. For this purpose, they used 1,10phenanthroline-5,6-dione $\mathrm{Q}_{4}$ in combination with $\mathrm{Znl}_{2}$ as an efficient cooperative system to promote, under $1 \mathrm{~atm}$ of $\mathrm{O}_{2}$ at room temperature, dehydrogenation of secondary amines and a diverse range of $\mathrm{N}$-heterocycles. ${ }^{[15]}$

In contrast, the biomimetic aerobic catalytic oxidation of non-activated primary alkylamines, that are natural substrates for CuAOs, ${ }^{[16]}$ has received little attention, probably because the generated alkylimines very easily isomerize into the unstable enamine tautomers. In 2012, we reported the first biomimetic aerobic catalytic oxidation of non-activated primary alkylamines through the synergistic combination of two redox couples: the oiminoquinone organocatalyst IMQ, previously discovered from electrochemical investigations, ${ }^{[17]}$ is the substrate-selective catalyst and the biocompatible copper salt serves as an electron transfer mediator. ${ }^{[18]}$ Although this system was capable to work under ambient air with high atom economy and was compatible with both activated benzylic and non activated aliphatic primary amines, some challenges still remained to be tackled. In particular, the use of a commercially available quinone-based organocatalyst would offer enhanced practicality. In this vein, novel strategies using simple low-cost precursors for quinone cofactor mimetics have been recently reported by the groups of Doris $\left(Q_{5}\right),{ }^{[19 a]}$ Carbery $\left(Q_{6}\right)^{[19 b]}$ and Oh $\left(Q_{7}\right){ }^{[19 c]}$ but these cooperative systems still require transition noble or non-noble biocompatible metal co-catalyst and, in most cases, they failed to oxidize non activated aliphatic primary amines. ${ }^{[19 b, c]}$

Since the oxidation of the primary amine substrates by CuAOs is mediated by TPQ without direct involvement of the copper ion, ${ }^{[4]}$ we thought that a more eco-friendly biomimetic organocatalytic method, avoiding contamination of the final products by metal residues, would be highly desirable but still challenging. In this paper, we describe an unprecedented bioinspired organocatalyzed cascade reaction, which allows the oxidative coupling of both activated and non activated primary amines to imines under ambient air.

At the beginning of our investigations, we were aware that commercially available quinone-based organocatalysts reminiscent of TPQ would not be sufficiently reactive to promote the aerobic oxidation of non activated primary amines without any additives. ${ }^{[9]}$ Based on our recent studies, ${ }^{[17,18]}$ we were drawn to the structure of natural purpurogallin $(2,3,4,6$-tetrahydroxy- $5 \mathrm{H}$ benzocyclohepten-5-one) $2_{\text {red }}$ as a potential precursor of a highly reactive o-quinone-based organocatalyst 2 ox because of the presence of the tropolone scaffold which should direct attack of the amine substrate at the 3-position of the generated o- quinone species $2_{\text {ox }}$ (Scheme 2). Even more crucial was the presence of an active hydroxyl group at the 4-position which had been proved to be an essential component of the catalytic activity associated with enzymatic ${ }^{[4,6]}$ and non enzymatic catalytic systems ${ }^{[17,20]}$ through the formation of a highly reactive $\mathrm{H}$-bonded cyclic transition state (CTS). However, the limited availability of purpurogallin $\mathbf{2}_{\text {red }}$ led us to concentrate on its well established biosynthesis which involves the oxidative dimerization of pyrogallol $\mathbf{1}_{\text {red }}$ generated from gallic acid. ${ }^{[21]}$

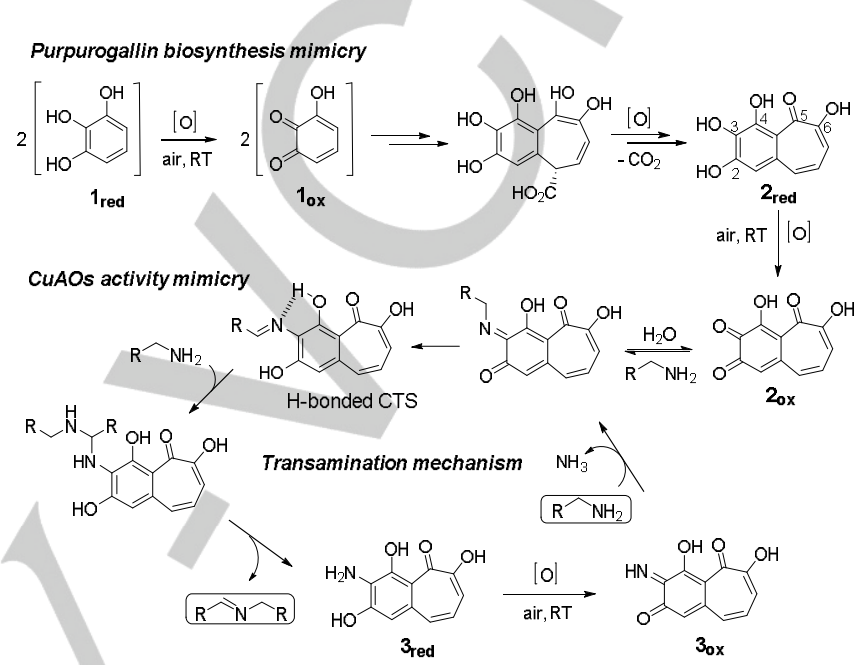

Scheme 2. Proposed bioinspired cascade reaction for the organocatalyzed aerobic oxidation of primary amines to imines under air

Based on this insight, we designed a double biomimetic reaction pathway for the chemoselective organocatalytic oxidative coupling of primary amines to imines under air as described in Scheme 2. The cascade reaction would involve aerobic oxidation of commercially available pyrogallol $\mathbf{1}_{\text {red }}$ to form the corresponding o-quinone $\mathbf{1}_{\text {ox }}$ which should then suffer homodimerization to yield the 6/7-fused bicyclic compound intermediate. The latter would afford purpurogallin $\mathbf{2}_{\text {red }}$ after decarboxylation and oxidation steps. Aerobic oxidation of $\mathbf{2}_{\text {red }}$ would then generate a highly reactive o-quinone species $\mathbf{2}_{\mathrm{ox}}$ which should be intercepted by the primary amine substrate to produce the reduced o-aminophenol form $3_{\text {red }}$ and homocoupled imine through the transamination process reported for CuAOs enzymes. The final step under single turnover would be the reoxidation of $\mathbf{3}_{\text {red }}$ to generate o-iminoquinone $\mathbf{3}_{\mathrm{ox}}$ which would react directly with the amine substrate leading to the Schiff-base $\mathrm{H}$-bonded CTS by passing $\mathbf{2}_{\text {ox }}{ }^{[5,69]}$

To evaluate the validity of this bioinspired cascade reaction sequence, we performed optimization studies by using 4methylbenzylamine $\mathbf{4}$ as the amine substrate. If our hypothesis is right, part of the reaction conditions should be identical to that required for the $\mathrm{Cu}^{\prime \prime} / \mathrm{IMQ}$-catalyzed cooperative process. ${ }^{[18 b]}$ Accordingly, a combination of one equivalent of amine 4 with 0.04 equivalent of pyrogallol $\mathbf{1}_{\text {red }}$ (corresponding to the generation of 2 mol\% of purpurogallin $2_{\text {red }}$ ) gave optimal results. As expected, after $24 \mathrm{~h}$, under ambient air, complete conversion into imine 5 (Scheme 3) was observed only in $\mathrm{MeOH}$, because strong solvation of the o-quinone $\mathbf{2}_{\mathrm{ox}}$ or o-iminoquinone $\mathbf{3}_{\mathrm{ox}}$ by $\mathrm{MeOH}$ was necessary to enhance the electrophilicity of its quinonoid moiety, thereby favoring the nucleophilic attack of the 
amine substrate. Then, $\quad N$-(4-methylbenzyl)-1-(ptolyl)methanimine $\mathbf{5}$ was obtained in $\mathbf{9 0 \%}$ isolated yield.
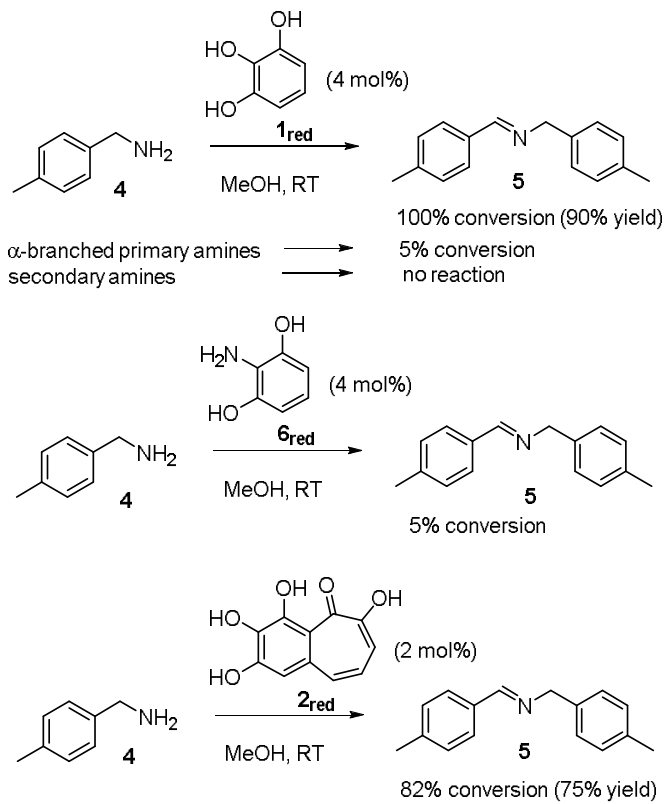

Scheme 3. Control studies

Control studies revealed that no reaction occurred under the same experimental conditions when $\mathbf{1}_{\text {red }}$ was fully omitted from the reaction mixture. Interestingly, as for natural CuAOs, $\alpha-$ branched amines such as sec-benzylamine were found to be poor substrates for the biomimetic organocatalyzed reaction with less than $5 \%$ conversion into imines, whereas secondary amines were not reactive at all (Scheme 3 ). These results were fully consistent with the enzymatic transamination mechanism and ruled out an addition-elimination process. Note that the transamination process could engage only $\mathbf{1}_{\text {ox }}$ by passing $\mathbf{2}_{\text {ox. }}$. To gain more insight into the cascade reaction, we examined the catalytic efficiency of o-iminoquinone $\mathbf{6}_{\text {ox }}$ generated in situ from 2 -aminoresorcinol $\boldsymbol{6}_{\text {red }}$ under the optimal reaction conditions. As previously reported from electrochemical studies, ${ }^{[17]}$ aerobic oxidation of $\boldsymbol{6}_{\text {red }}$ produced a poorly reactive 0 -iminoquinone catalyst $\mathbf{6}_{\mathrm{ox}}$ which mainly decomposed to melanin-like polymers, giving only $5 \%$ of imine $\mathbf{5}$. In contrast, when purpurogallin $\mathbf{2}_{\text {red }}$ was utilized as the starting material for producing $\mathbf{2}_{\mathrm{ox}}$, high catalytic activity was observed at the early stages of the reaction. Nevertheless, under aerobic conditions, the instability of the highly reactive o-quinone $\mathbf{2}_{\mathrm{ox}}$ which slightly decomposed finally led to a decreased yield of imine $\mathbf{5}(\mathbf{7 5 \%})$ when compared to that obtained when $\boldsymbol{1}_{\text {red }}$ was used as the starting material (90\%). Most likely, when starting from $\mathbf{1}_{\text {red, }}$, the continuously low concentration of the in situ generated o-quinone $\mathbf{2}_{\text {ox }}$ should protect it against the polymerization reaction.

We further explored the scope of this cascade reaction by focusing on the oxidative cross-coupling of primary amines which is known to be a challenging transformation ${ }^{[10,18,19]}$ as selfcoupling is usually preferred. For this reason, the catalytic oxidative coupling of alcohols and amines reigns supreme although, with few exceptions, ${ }^{[22]}$ this method generally requires elevated temperature, oxygen pressure or expensive metals. Optimization of the reaction parameters showed that mixing 4methylbenzylamine $\mathbf{4}$ and sec-benzylamine in the ratio 1:1 upon increasing pyrogallol loading ${ }^{[10,19 \mathrm{~b}]}$ to $10 \mathrm{~mol} \%$ (8 mol\% followed by $2 \mathrm{~mol} \%$ after $24 \mathrm{~h}$ ) thus generating $5 \mathrm{~mol} \%$ of $3_{\mathrm{ox}}$, in $\mathrm{MeOH}$, at $25^{\circ} \mathrm{C}$, under ambient air, gave exclusive formation of the desired cross-coupled imine 7 in $90 \%$ isolated yield after $60 \mathrm{~h}$ (Table 1). The real-time monitoring of the cross-coupling reaction by ${ }^{1} \mathrm{H}$ NMR spectroscopy indicated that the homocoupled product $\mathbf{5}$ was initially formed and accumulated during the first hours of the reaction. Then, it gradually converted into the cross-coupled product 7 to become the exclusive product. These observations indicated that 7 was obtained through the transamination process reported in Scheme 2, which leads to the homocoupled imine intermediate $\mathbf{5}$, followed by dynamic transimination. ${ }^{[10,18,19]}$ Just one equivalent of each primary amine was sufficient to achieve exclusive transformation into the cross-coupled imine 7 through the well-known oxidative self-sorting process which has widely been exploited to obtain thermodynamically disfavored products. ${ }^{[10,23]}$ As shown in Table 1, a broad range of substituted benzylic amines were tolerated, including those bearing electron-donating groups (products 11-13), electron-withdrawing groups (products 14, 15, and 19) or fluorine (product 17). A thiophene moiety was also tolerated (product 20), as was furfurylamine which allowed the exclusive formation of the crosscoupled imine 21. Both branched and linear aliphatic amines could be efficiently coupled with benzylic amines in high isolated yields, within 24-60h depending on the basicity of the crosscoupled amine $\mathrm{R}^{\prime}-\mathrm{NH}_{2}$. Complete selectivity was observed except for aminomethylcyclohexane (product 10) and $n$ hexylamine (product 13), for which small amounts of homocoupled imine $(7 \%)$ were also isolated. As observed earlier, ${ }^{[10,18 \mathrm{~b}]}$ poor nucleophilic 4-methoxyaniline afforded crosscoupled imine in only $55 \%$ isolated yield (product 9 ) as the conversion did not exceed $68 \%$ after $60 \mathrm{~h}$.

The synthesis of aliphatic imines was intrinsically more challenging because of their relative instability and isomerization into the enamine tautomer which decomposes under ambient air. ${ }^{[18 b, 24]}$ Nevertheless the reaction conditions used through this bioinspired cascade reaction sequence were favorable for trapping the generated unstable alkylimines in situ for further reactions. So, in a second series of experiments, we examined the aerobic oxidative cross-coupling of a range of non-activated primary aliphatic amines with $\mathrm{N}$-methyl-o-aminoaniline as an in situ imine trap (Table 1). ${ }^{[25]}$ This was not a trivial exercise because this reaction had proved to be unsuccessful in the

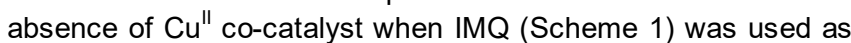
the sole organocatalyst. ${ }^{[25 b]}$ Pleasingly, at $60^{\circ} \mathrm{C}$ (See Table S1 in the Supporting Information), the organocatalyst $\mathbf{3}_{\text {ox }}$ was sufficiently reactive to activate, under ambient air, the $\alpha-C-H$ bond of diverse primary aliphatic amines to give 1,2disubstituted benzimidazoles 22-27 in good yields, except for sterically constrained $\beta$-branched alkylamine for which the yield did not exceed $52 \%$ (product $\mathbf{2 8}$ ).

Recently, it has been reported that the evolutionary selection of viable quinone-based redox cofactors appears strongly linked to the ability of the catalytically produced quinols to undergo facile reoxidation back to their starting quinones. ${ }^{[4]}$ Accordingly, the results of this study clearly highlight the ability 
of $\mathbf{3}_{\text {red }}$ to undergo oxidation to $\mathbf{3}_{\text {ox }}$ which occurs under ambient air, without the assistance of electron transfer mediator. In addition, its catalytic efficiency is enhanced through the participation of both tropolone scaffold and 4-hydroxy substituent in directing the nucleophilic attack of the amine substrate at the 3-position of $\mathbf{3}_{\text {ox. }}$. Also, the presence of the active 4-hydroxy group, which is engaged in an intramolecular hydrogen bond with the imine nitrogen to form a highly reactive Schiff base CTS (Scheme 2) is of overriding importance for the development of the catalytic process. ${ }^{[20]}$ The combination of all these elements allows the oxidation of non-activated primary aliphatic amines that until now remained challenging substrates for nonenzymatic organocatalysts.

Table 1. Insight into the substrate scope of the $3_{\mathrm{ox}}$-mediated aerobic oxidative cross-coupling of amines.
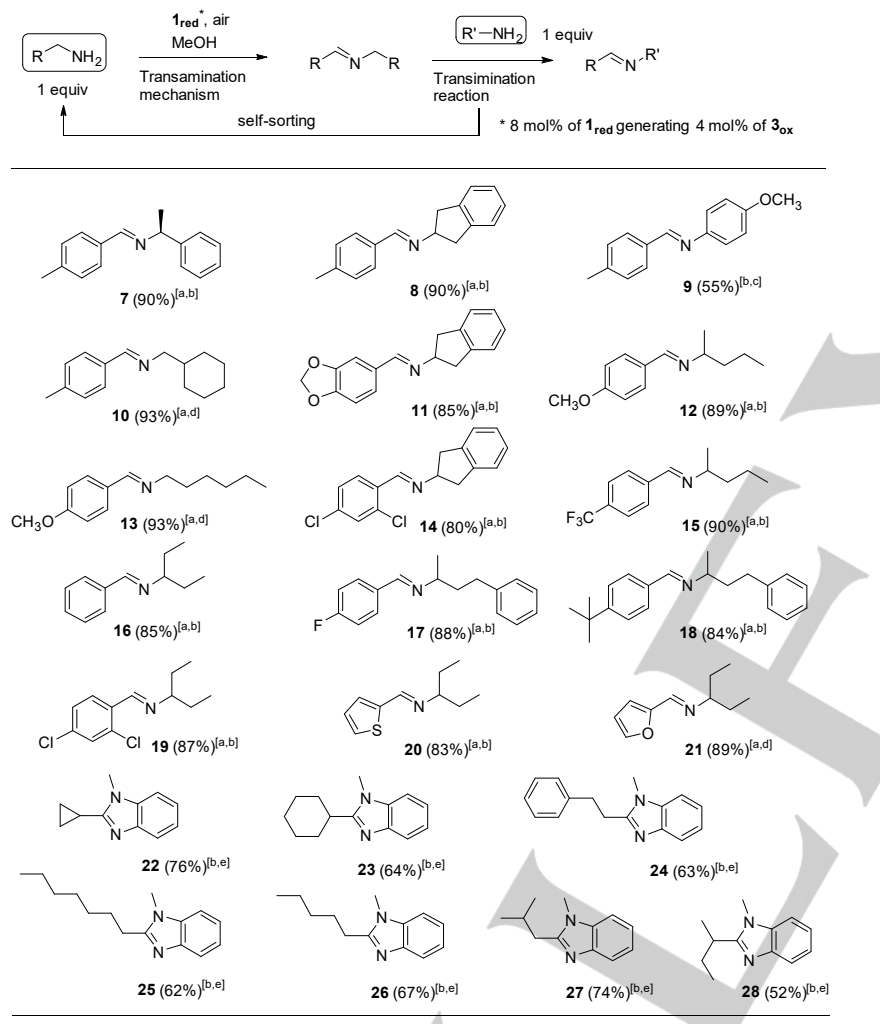

[a] $25^{\circ} \mathrm{C}, 100 \%$ conversion, reaction times: $24 \mathrm{~h}$ for $10,12,13,15,16,19$ and $20 ; 48 \mathrm{~h}$ for 21 and $60 \mathrm{~h}$ for 7-9, 11, 14, 17 and 18; additional aliquot of $1_{\text {red }}(2 \mathrm{~mol} \%)$ was added after $24 \mathrm{~h}$. [b] isolated yields after column chromatography. [c] $68 \%$ conversion. [d] yields of the cross-coupled imine were determined by $1 \mathrm{H}$ NMR. In the case of 10 and 13 , analysis of the reaction mixture indicated the presence of $7 \%$ of the corresponding homocoupled imine. [e] $60^{\circ} \mathrm{C}, 100 \%$ conversion, reaction time 60h; additional aliqu

In summary, we have developed a bioinspired organocatalytic cascade reaction for the activation of the $\alpha-\mathrm{C}-\mathrm{H}$ bond of primary amines which are converted to cross-coupled imines under exceptionally mild conditions. The reaction sequence starts from inexpensive commercially available pyrogallol $\mathbf{1}_{\text {red }}$ and allows, under ambient air, the in situ formation of not easily accessible natural purpurogallin $\mathbf{2}_{\text {red }}$ which is further engaged in the CuAOs enzymatic transamination process for producing, under single turnover conditions, the active biomimetic organocatalyst $3_{\text {ox }}$ and the homocoupled imine intermediate, followed by dynamic transimination. Noteworthy, the present organocatalytic cascade reaction, which has been inspired by both purpurogallin biosynthesis and copper amine oxidases activity, would not be easily conceivable at this level of complexity from first chemical concepts.

Keywords: biomimetics $\cdot$ cross-coupling $\cdot$ imines $\cdot$ organocatalysis $\cdot$ primary amines

[1] For a review, see: J. Piera, J.-E. Bäckvall, Angew. Chem. 2008, 120 3558-3576; Angew. Chem. Int. Ed. 2008, 47, 3506-3523.

[2] For a review, see: L. Que Jr; W. B. Tolman, Nature 2008, 455, 333-340

[3] S. M. Janes, D. Mu, D. Wemmer, A. J. Smith, S. Kaur, D. Maltby, A.L. Burlingame, J. P. Klinman, Science, 1990, 248, 981-987.

[4] For a review, see: J. P. Klinman, F. Bonnot, Chem. Rev. 2014, 114, 4343-4365

[5] E. M. Shepard, D. M. Dooley, Acc. Chem. Res. 2015, 48, 1218-1226.

[6] For a review, see: a) M. Mure, Acc. Chem. Res. 2004, 37, 131-139. See also: b) Y. Lee, L. M. Sayre, J. Am. Chem. Soc. 1995, 117, 3096-3105; c) M. Mure, J. P. Klinman, J. Am. Chem. Soc. 1995, 117, 8698-8706; d) M. Mure, J. P. Klinman, J. Am. Chem. Soc. 1995, 117, 8707-8718; e) Y. Lee, L. M. Sayre, J. Am. Chem. Soc. 1995, 117, 11823-11828; f) K. Q. Ling, J. Kim, L. M. Sayre, J. Am. Chem. Soc. 2001, 123, 9606-9611; g) M. Mure, S. A. Mills, J. P. Klinman, Biochemistry, 2002, 41, 9269-9278.

[7] For a comprehensive recent review, see: a) B. Chen, L. Wang, S. Gao, ACS catal. 2015, 5, 5851-5876; see also b) M. T. Schümperli, C Hammond, I. Hermans, ACS Catal. 2012, 2, 1108-1117; c) R. D. Patil, S. Adimurthy, Asian J. Org. Chem. 2013, 2, 726-744; d) M. Largeron, Eur. J. Org. Chem. 2013, 5225-5235; e) X. Lang, W. Ma, C. Chen, H. Ji, J. Zhao, Acc. Chem. Res. 2014, 47, 355-363; f) X. Lang, X. Chen, J. Zhao, Chem. Soc. Rev. 2014, 43, 473-486; g) B. L. Ryland, S. S. Stahl, Angew. Chem. Int. Ed. 2014, 53, 8824-8838; Angew. Chem. 2014, 126, 8968-8983.

[8] M. Largeron, M. -B. Fleury, Science, 2013, 339, 43-44.

[9] For a comprehensive recent review, see: A. E. Wendlandt, S. S. Stahl, Angew. Chem. 2015, 127, 14848-14869; Angew. Chem. Int. Ed. 2015 54, 14638-14658.

[10] A.E. Wendland, S. S. Stahl, Org. Lett. 2012, 14, 2850-2853.

[11] Y. Qin, L. Zhang, J. Lv, S. Luo, J.-P. Cheng, Org. Lett. 2015, 17, 1469-1472.

[12] H. Yuan, W.-J. Yoo, H. Miyamura, S. Kobayashi, J. Am. Chem. Soc 2012, 134, 13970-13973.

[13] D. V. Jawale, E. Gravel, N. Shah, V. Dauvois, H. Li, I. N. N Namboothiri, E. Doris, Chem. Eur. J. 2015, 21, 7039-7042.

[14] Y. Lee, K. -Q. Ling, X. Lu, R. B. Silverman, E. M. Shepard, D. M. Dooley, L. M. Sayre, J. Am. Chem. Soc. 2002, 124, 12135-12143.

[15] a) A. E. Wendlandt, S. S. Stahl, J. Am. Chem. Soc. 2014, 136 , 506-512; b) A. E. Wendlandt, S. S. Stahl, J. Am. Chem. Soc. 2014, 136, 11910-11913.

[16] V. J. Klema, C. J. Solheid, J. P. Klinman, C. M. Wilmot, Biochemistry, 2013, 52, 2291-2301.

[17] M. Largeron, A. Chiaroni, M.-B. Fleury, Chem. Eur. J. 2008, 14 996-1003.

[18] a) M. Largeron, M.-B. Fleury, Angew. Chem. 2012, 124, 5505-5508 Angew. Chem. Int. Ed. 2012, 51, 5409-5412; b) M. Largeron, M.-B. Fleury, Chem. Eur. J. 2015, 21, 3815-3820.

[19] a) D. V. Jawale, E. Gravel, E. Villemin, N. Shah, V. Geertsen, I. N. N Namboothiri, E. Doris, Chem. Commun. 2014, 50, 15251-15254; b) A T. Murray, R. King, J. V. G. Donnelly, M. J. H. Dowley, F. Tuna, D. Sells, 
M. P. John, D. R. Carbery, ChemCatChem, 2016, 8, 510-514; c) Y Goriya, H. Y. Kim, K. Oh, Org. Lett. 2016, 18, 5174-5177.

[20] D. W. C. MacMillan, Nature, 2008, 455, 304-308.

[21] a) W. Dürckheimer, E. F. Paulus, Angew. Chem. Int. Ed. Engl. 1985, 24, 224-225; b) P. Ellerbrock, N. Armanino, M. K. Ilg, R. Webster, D. Trauner, Nat. Chem. 2015, 7, 879-882.

[22] a) H. Tian, X. Yu, Q. Li, J. Wang, Q. Xu, Adv. Synth. Catal. 2012, 354 2671-2677; b) A. Mukherjee, A. Nerush, G. Leitus, L. J. W. Shimon, Y. Ben David, N. A. Espinosa Jalapa, D. Milstein, J. Am. Chem. Soc. 2016 138, 4298-4301.

[23] For a review, see: a) M. E. Belowich, J. F. Stoddart, Chem. Soc. Rev. 2012, 41, 2003-2024. See also: b) S. M. Landge, V. Atanassova, M. Thimmaiah, B. Török, Tetrahedron Lett. 2007, 48, 5161-6164.
[24] a) Y. Endo, J.-E. Bäckvall, Chem. Eur. J. 2012, 18, 13609-13613; b) S Morales, F. G. Garcia Ruano, M. B. Cid, J. Am. Chem. Soc. 2014, 136 1082-1089; c) D. B. Ushakov, M. Plutschack, K. Gilmore, P. H. Seeberger, Chem. Eur. J. 2015, 21, 6528-6534.

[25] a) K. M. H. Nguyen, M. Largeron, Chem. Eur. J. 2015, 21, 1260612610; b) K. M. H. Nguyen, M. Largeron, Eur. J. Org. Chem. 2016, 1025-1032. 


\section{Entry for the Table of Contents}

\section{Layout 1: Bioinspired Organocatalytic Cascade}

\section{COMMUNICATION}

Dual mimicking of purpurogallin biosynthesis and copper amine oxidases activity allows the chemoselective oxidative crosscoupling of primary amines to imines under environmentally benign metalfree conditions

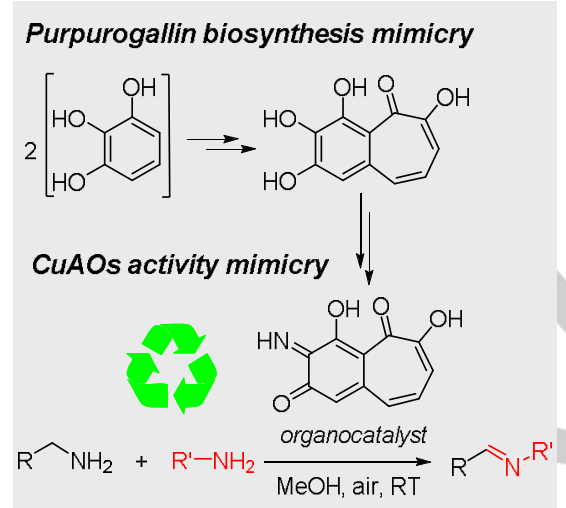

M. Largeron, ${ }^{*}$ M. - B. Fleury

Page No. - Page No.

A Bioinspired Organocatalytic

Cascade for the Selective Oxidation of Amines under Air 